\title{
An update about neck rejuvenation and complications
}

\author{
Fausto Viterbo ${ }^{1,2}$, Murilo Sgarbi Secanho ${ }^{1}$ \\ 'Division of Plastic Surgery, University of the State of São Paulo (UNESP), Botucatu, São Paulo 18607-030, Brazil. \\ ${ }^{2}$ Dr. Fausto Viterbo's Plastic Clinic. Botucatu, Botucatu, São Paulo 18607-030, Brazil.
}

Correspondence to: Dr. Fausto Viterbo, Division of Plastic Surgery, University of the State of São Paulo (UNESP), Rua Domingos Minicucci Filho, 587 Bairro São Judas Tadeu, CEP 18607-030, Botucatu, São Paulo 18607-030, Brazil.

E-mail: faustoviterbo@hotmail.com

How to cite this article: Viterbo F, Secanho MS. An update about neck rejuvenation and complications. Plast Aesthet Res 2021;8:61. https://dx.doi.org/10.20517/2347-9264.2021.16

Received: 26 Feb 2021 First Decision: 22 Mar 2021 Revised: 7 Jun 2021 Accepted: 18 Nov 2021 Published: 5 Dec 2021

Academic Editors: Wen-Guo Cui, Raúl González-García Copy Editor: Xi-Jun Chen Production Editor: Xi-Jun Chen

\begin{abstract}
The submental-cervical angle is an important anatomical landmark in neck beauty. Considered attractive and a sign of youthful when between $105^{\circ}$ and $120^{\circ}$, greater values are considered a "heavy" neck or double chin and are related to the aging process and/or weight gain. The submandibular gland can also contribute to the alteration of the submental-cervical angle, increasing the area's bulging. Neck-lifting techniques have the potential to produce important changes in the lateral view of the face, making it look more youthful, and that is more noticeable in the frontal aspect. This review focuses on the treatment of the neck, including all modifications that occur during the aging process, and postoperative procedures used to decrease the risk of complications.
\end{abstract}

Keywords: Facial rejuvenation, neck rejuvenation, neck lift, neck lifting, hemostatic net, blunt dissectors

\section{INTRODUCTION}

During the aging process, the face and neck suffer structural alterations, leading to considerable changes. The skin loses elasticity due to epidermal thinning and a decrease in collagen. The facial contour is affected by the loss of fat or hypertrophy and ligament laxity. Face muscles increase in length and tone, and their movements have shorter amplitude. Facial bones are reabsorbed, losing projection and support. These 
morphological changes lead to skin laxity, permanent skin wrinkling, static facial lines, and a sagging appearance of an aging face $e^{[1-5]}$.

The submental-cervical angle is an important anatomical landmark in neck beauty. It is considered attractive and a sign of youth when it falls between $105^{\circ}$ and $120^{\circ[6]}$. Greater values are considered a "heavy" neck or double chin and are related to aging and/or weight gain and unfavorable muscle anatomy ${ }^{[6]}$. The volume of the submandibular gland - which is influenced by weight gain, alcohol intake, eating disorders, and the aging process ${ }^{[7]}$ - can also contribute to the alteration of the submental-cervical angle, by increasing the area's bulging.

Increasing knowledge of the aging process and the anatomical structures of the neck have led to more sophisticated techniques in the treatment of facial aging, which have evolved to the deep-plane approach $^{[3-5]}$. Methods used to prevent complications involved with neck-lifting procedures have also advanced, leading to better outcomes. Despite this evolution, it appears literature reviews are limited. To address this gap, this article aims to provide an overview of various surgical techniques used in neck rejuvenation, including the prevention of related complications.

In the first part of this article, we present the diversity of surgical options described in the literature to rejuvenate the neck. Then, we discuss the main potential complications involved with neck-lifting procedures. In the last section, we provide an overview of the hemostatic net, which is increasingly being used after neck and face lifting procedures.

\section{NECK-LIFTING PROCEDURES}

Neck-lifting procedures result in a more youthful appearance from the lateral view of the neck and the frontal aspect of the face ${ }^{[8]}$. The preoperative assessment of the neck-lifting procedure includes an analysis of all anatomical compartments, including those from the $\operatorname{skin}^{[9]}$. A conservative approach may first focus on dermatological interventions. This can typically include the use of retinoids, alpha hydroxy acids, ascorbic acids, growth factors, heparan sulfate, and pigmentation as options to approach extrinsic and intrinsic factors related to skin aging alterations ${ }^{[10]}$. Skin laxity can be treated with injectables, such as calcium hydroxyapatites and poly-l-acid lactic ${ }^{[1,12]}$, micro-focused ultrasound ${ }^{[13]}$, and laser therapy ${ }^{[14]}$.

Neck and facial lifting are the surgical options. They can be managed by incision, skin detachment, traction, and resection. The traction vector may vary according to the surgeon's preference - obliquely, horizontally, or vertically ${ }^{[15,16]}$. The place of the incision can also vary - post- or pre-auricular and in front or behind hair implantation ${ }^{[17]}$.

The enlarged submental-cervical angle combined with fat tissue accumulation can be treated with liposuction and/or submental incision associated with direct lipectomy ${ }^{[9,18,19]}$. Liposuction can address the supra-platysmal fat, but, in most cases, it cannot achieve an optimal result alone $\mathrm{e}^{[9]}$. Submental incision can treat all the neck fat layers (supra-platysmal, inter-platysmal, and infra-platysmal), resulting in a neck that is commonly attractive to many patients ${ }^{[9,20]}$. These interventions can be performed independently in patients with excellent skin tone, no laxity or lipodystrophy, and with other procedures such as skin resection and plicatures when skin laxity and platysmal bands are present ${ }^{[2,22]}$. Caution should be exercised however to avoid the removal of excess tissue and hollowed and rippling appearance ${ }^{[23]}$. 
The submandibular gland is located laterally in the junction of the digastric muscle and the hyoid, and it is enclosed by a capsule derived from deep fascia ${ }^{[24]}$. A gland with ptosis and a modestly increased volume can be repositioned across the posterior digastric muscle tendon. When hypertrophy is diagnosed, partial resection is also indicated. The superficial lobe is isolated and resected. The amount of gland to be removed is limited to that exceeding the line between the lowest point of the anterior belly of the digastric muscle and the inferior border of the mandible. This procedure requires careful and precise coagulation in order to prevent hematomas ${ }^{[25-27]}$. The artery and vein penetrate the capsule at the posterolateral location that has a central artery perforator crossing from the deep to the superficial lobe. The perforator can retract and suffer spasms if transected during surgery, causing bleeding that may be hard to control ${ }^{[24]}$. Other complications related to this procedure involve sialoma, salivary fistula, dry mouth, and weakness of lower lip depressor ${ }^{[25-27]}$. To prevent sialoma and salivary fistula, some plastic surgeons inject botulin toxin directly into the gland in order to decrease the production of saliva. From our experience dealing with submandibular and parotid gland, we do not use botulin toxin. Instead, we recommend a non-acid and low sugar diet for three weeks during postoperative care; our incidence of complications has been virtually nil.

The surgical approach to muscle is another maneuver for cervical lifting. Platysmal bands could be hypertrophic, hypotonic, and pseudobands (only skin folds) ${ }^{[28]}$. A complete horizontal transection has satisfactory results. However, it has a high risk of iatrogenic deformities, and there is a significant risk of failure when it comes to maintaining long-term results ${ }^{[28]}$. An association of horizontal transection in the medial platysma with Z-plasty and a corset procedure has shown adequate and consistent results ${ }^{[29]}$. Another method is the closed platismotomy, in which the bands are cut without incision; this can be performed with local anesthesia. Using a needle and suture, the surgeon involves the muscle, and the sawlike back-and-forth motion ruptures the band ${ }^{[30-32]}$. However, even with these options, the bands can recur; an insufficient approach to posterior platysma fascia, muscle regeneration, and metameric innervation are all possible causes ${ }^{[33,34]}$.

The corset technique involves suturing the platysma in a way that improves the contouring of the neck, tightening its structure ${ }^{[35]}$. First described by Feldman in 1988, the medial borders are placed together by a two running-way suture ${ }^{[22,35]}$.

Ramirez $^{[36]}$ (1997) described an anterior approach, by the submental crease, in a mixed open and endoscopic technique. To provide a smooth and flat contour to the submental area, all three cervical fat pads are removed directly, and the digastric muscle is plicated in the midline. The medial borders of platysma are resected after a maneuver of advancement, and both are sutured in conjunction in a corset style from the level of the thyroid cartilage to the mandibular symphysis.

Labbé et al. ${ }^{[37]}$ (2013) presented the suprahyoid corset, a running suture between the anterior belly of the digastric muscle anchoring at the mylohyoid muscle, associated with the corset of the platysma muscle. It can address mylohyoid malposition, tighten mouth floor, remove the suprahyoid subplatysmal fat layer, and lead to a deep and well-defined cervical angle [Figures 1-5].

The platysma can also be managed laterally with cable sutures. Labbé et al. ${ }^{[38]}$ (2006) developed a technique in which the platysma is sutured in the Lorés fascia, and with this traction the muscle can be replaced $4 \mathrm{~cm}$ higher, improving the cervical contour. Fogli ${ }^{[39]}$ (2008) described a platysma muscle anchoring in the prelobar fibrous tissue. Gonzalez ${ }^{[40]}$ (2014) utilized an overlapping plication of platysma. After a vertical incision and small blunt detachment, the lateral edge of the platysma muscle is pulled posteriorly and cephalically, fixating it just below the mandible angle. 

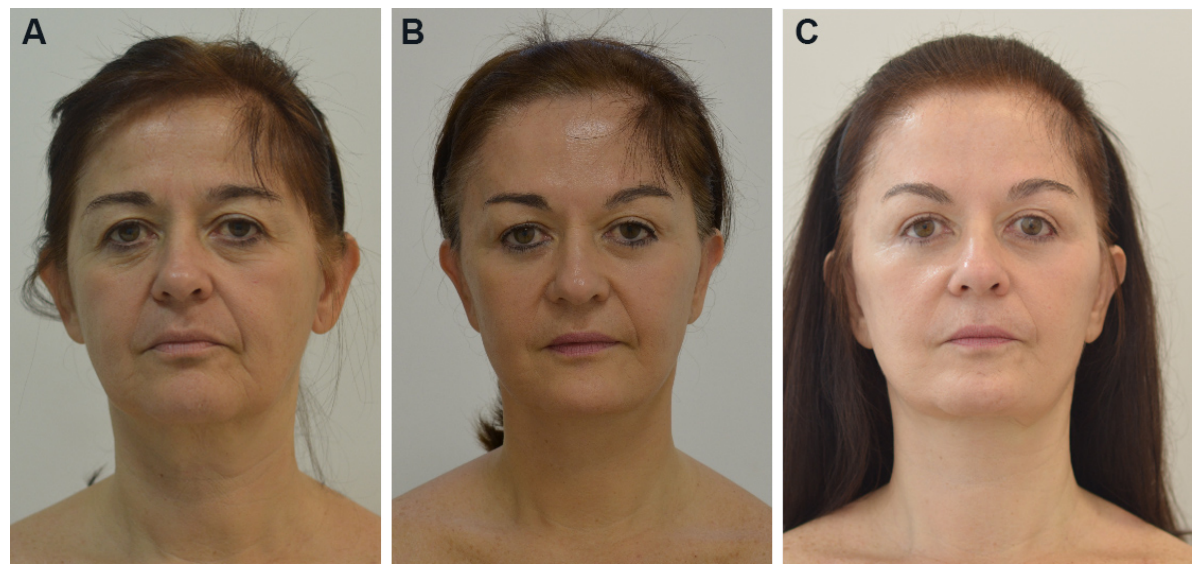

Figure 1. A 55-year-old patient was submitted to gliding brow lift, cervical and facial lifting with large skin detachment, superficial musculoaponeurotic system plicatures, submental fat removal, digastric and platisma medial plicature, and orbicularis oculli myectomy. (A) Preop; (B) nine months postop; and; (C) two years and three months postop.
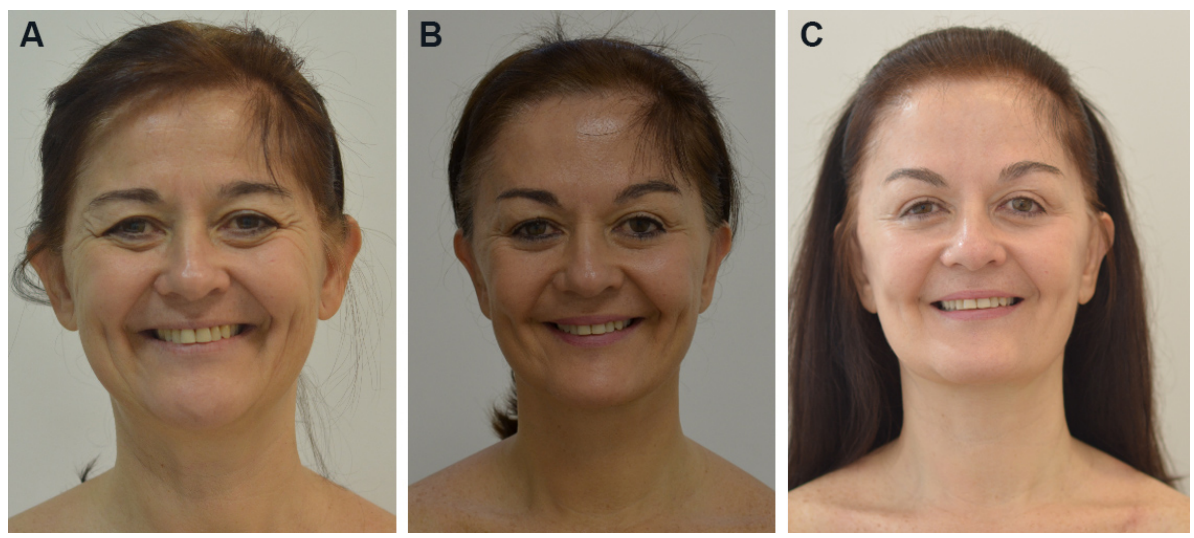

Figure 2. Preoperative and postoperative photography: (A) preop; (B) nine months postop; and (C) two years and three months postop.
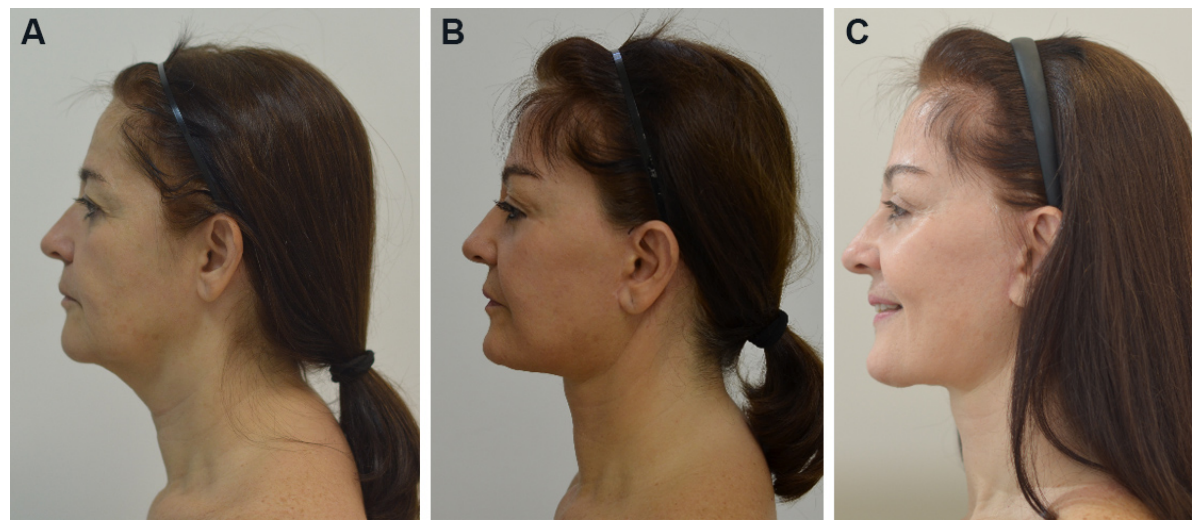

Figure 3. Preoperative and postoperative photography: (A) preop; (B) nine months postop; and (C) two years and three months postop.

\section{COMPLICATIONS}

During the postoperative period, hematomas are common complications, occurring in approximately $0.2 \%$ $8.0 \%$ of patients ${ }^{[4]}$. Minor hematomas $(2-10 \mathrm{cc}$ ) are typically and spontaneously absorbed in one or two 

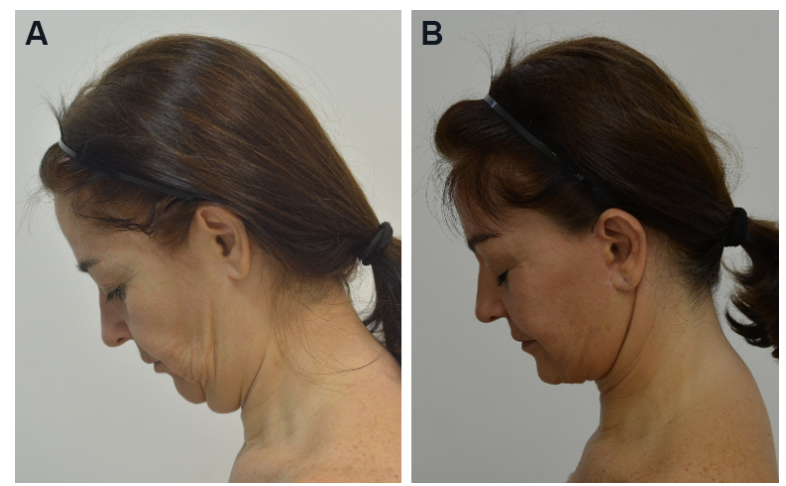

Figure 4. Preoperative and postoperative photography: (A) preop; and (B) nine months postop.
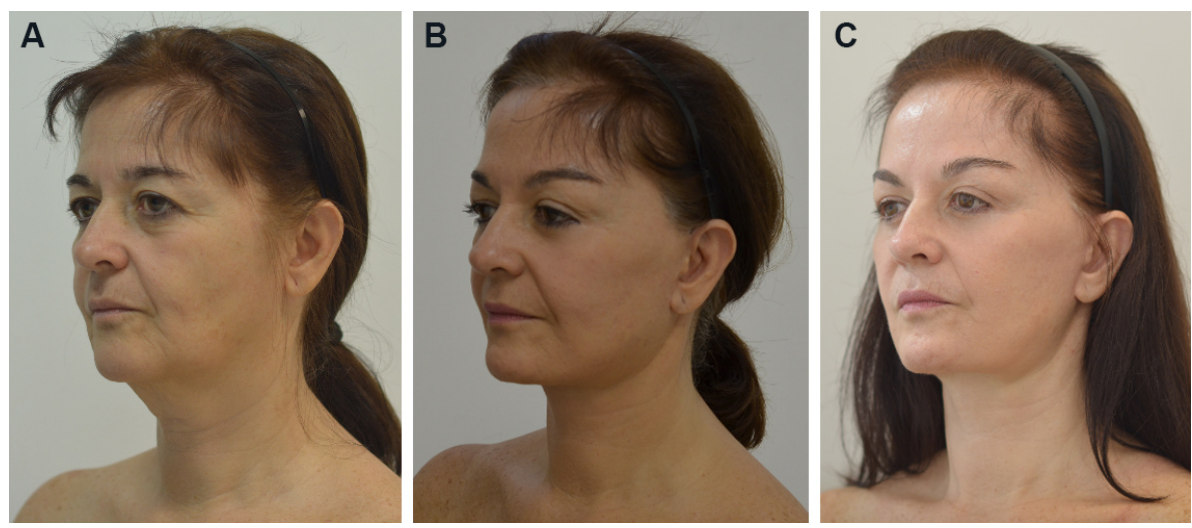

Figure 5. Preoperative and postoperative photography: (A) preop; (B) nine months postop; and (C) nine months postop.

weeks when massage is involved. They can also be aspirated using local anesthesia. However, minor hematomas do have the potential to cause small irregularities, mainly in the mastoid and periauricular areas, and hyperpigmentation ${ }^{[2,43]}$. Large hematomas, on the other hand, can lead to skin necrosis, prolonged edema, bruising, delayed wound healing, infections, emotional distress, and in extreme cases respiratory impairment by airway compression ${ }^{[44,45}$. Large hematomas demand timely diagnosis and treatment, where surgical re-intervention using general anesthesia may be required to evacuate clots and coagulate bleeding vessels.

The average time where complications typically occur is $24 \mathrm{~h}$ after surgery ${ }^{[42,46]}$. The medical staff should be aware of indicative symptoms during this time. They commonly include pain, nausea, tenderness in the face and neck, eversion of lips, and discoloration of oral mucosa ${ }^{[47]}$.

High blood pressure during the pre-, intra-, or peri-operative period is the most significant risk factor of hematomas after face- and neck-lifting procedures ${ }^{[41,44]}$. Systolic values greater than $160 \mathrm{mmHg}$ before and higher than $150 \mathrm{mmHg}$ after surgery increase the risk of bleeding ${ }^{[48]}$. Gender is another important factor. In males, facial skin is thicker and more vascularized due to the beard follicles and sebaceous gland vascular supply, leading to a higher risk of hematoma ${ }^{[42]}$. Smoking and some medications, including aspirin, gingko biloba, non-steroidal anti-inflammatory drugs, and fish oil, can also increase the risk of hematomas ${ }^{[49]}$. 
Anterior platysmaplasty has been proven to be a risk factor of hematomas; extended undermining, mid-line involvement, and increase in venous pressure by corset are possible reasons for the increase in risk ${ }^{[44]}$.

Although various methods have been used to prevent hematomas after surgery, none has been demonstrated to be completely effective ${ }^{[45]}$. Surgical drains, for example, do not necessarily prevent hematomas, and when removed they can actually cause hematomas - even with suction release ${ }^{[4,50]}$. Tissue sealants may decrease the risk of hematomas; however, the literature appears inconsistent and limited. In addition to the high cost, tissue sealants have the potential to cause allergic reactions and transmit infectious diseases $^{[51-53]}$. Compressive dressing is another method used to prevent complications. However, they have the potential to compromise flap vascularization, in addition to being uncomfortable ${ }^{[46]}$.

An important complication that can occur during face and neck lifting is nerve injury. It can happen with nerve transection by scissors or scalpel, thermal injury, suture plication, or deep dissection in the superficial musculoaponeurotic system (SMAS) or platysma in the danger zones ${ }^{[54-56]}$.

The most common nerve injury is to the great auricular nerve, occurring in $6 \%$ of cases. It can be transient, with self-resolution within 6-12 months. However, if the injury leads to neuroma formation and unabated pain, it can only be resolved with resection ${ }^{[57]}$. This nerve is more vulnerable at Mckinney's point located $6.5 \mathrm{~cm}$ below the external auditory canal crossing the mid belly of the sternocleidomastoid muscle, where it becomes more superficial ${ }^{[54]}$.

Motor nerve injury is mostly related to marginal mandibular lesion in cervicofacial lifting ${ }^{[49]}$. It can lead to palsy or weakness of the lower lip depressor, leaving it up and flat ${ }^{[56]}$. In a large proportion of cases, it is selflimited and caused by traction ${ }^{[49]}$. The area that extends from the angle of the mandible to its crossing by the anterior facial artery and from the inferior border of the mandible to a parallel line $3 \mathrm{~cm}$ below should be dissected carefully ${ }^{[55]}$.

A less common injury may happen in the cervical branch of the facial nerve. It can be clinically distinguished from the marginal mandibular lesion because it does not affect the mentalis muscle; thus, the patient is able to evert the lower lip ${ }^{[5]}$. The injury is more susceptible in the platysma superolateral border in the deep-plane approach ${ }^{[5]}$. Over the zygomatic arch, the temporal nerve runs deep to the SMAS, so care should be taken when approaching this area ${ }^{[49]}$. Zygomatic and buccal branches can also be injured during rhytidectomy - the last in the loose areolar tissue anterior to the parotid gland. However, the extensive branching system makes a spontaneous recovery expected when an injury occurs ${ }^{[57]}$.

Skin necrosis is another complication that could be present in $1 \%-3 \%$ of rhytidectomies. It typically occurs in pre and post auricular areas, where the flap is thinnest, presents more tension, and is more distant from blood supply ${ }^{[2,57]}$. The cause of skin necrosis is venous congestion or artery compromise, which are commonly related to edema, hematoma, infection, subdermal plexus damage, diabetes, radiation therapy, and smoking. As a main risk factor, smoking can increase the risk of necrosis by $12-20$ folds $^{[23,57,58]}$.

The skin is usually detached with scissors. In the distal part of the flap, near the ear, the surgeon is able to properly control the flap thickness. As the procedure evolves, the proximal detachment can turn more superficial, which increases the risk of necrosis, or deeper, which may lead to nerve injury. To minimize or prevent these risks, some surgeons have used blunt techniques and instruments to skin detachment. Vasconez ${ }^{[59]}$ used a needle holder, da Luz et al. ${ }^{[60]}$ used cylindrical progressive diameter enlargement detachers, Trepsat scissors adapted to a heart shape in the tip plaques ${ }^{[1]]}$, and Viterbo ${ }^{[62]}$ used Trepsat 
scissors in which the closing hand movements are done to compress the handle's dissector to perform blunt detachment [Supplementary Videos 1 and 2, Figure 6]. All these blunt-tipped instruments allow a safe dissection below the subdermal vascular plane. They minimize the risk of trauma in the vascular dermis plexus, decrease the nerve injury rate, and avoid changes in the facial layer during movements and transected lesions ${ }^{[59-62]}$.

Flap necrosis is typically identified in the first $24-48 \mathrm{~h}$ after surgery. To prevent this complication, we recommend local compression and decompression massage immediately after surgery. If there is any color alteration in the skin as purple or pallor, this maneuver should continue throughout the first $24 \mathrm{~h}$ or even $72 \mathrm{~h}$ after surgery ${ }^{[57,58]}$.

Similar to other rhytidectomy complications, prevention of flap necrosis is the preferable strategy. As mentioned above, a carefully and safely performed dissection using proper instruments and techniques decreases the risk of complications. A proper incision and multilayer sutures aid in avoiding tension in the flap. The patient is oriented to quit smoking four weeks before and after surgery, in addition to carefully explaining the risk of developing complications ${ }^{[57,58]}$.

In the postoperative care, the patient should avoid any physical and stressful activities for four weeks, stay in semi-sitting position during the day for a week, and take analgesics. The patient can wash his/her hair $24 \mathrm{~h}$ after surgery. If non-absorbable sutures are placed, they should be removed in 7-14 days. All potential complications, including unexpected pain, bruising, and bulging, should be carefully explained to the patient and monitored by the patient to seek medical advice if they occur ${ }^{[63]}$.

\section{THE HEMOSTATIC NET}

Based on the quilting suture technique used in abdominoplasty, as popularized by Baroudi and Ferreira ${ }^{[64]}$, which aims to decrease the "dead space" and minimize the incidence of hematomas and seromas, and on transfix sutures for flap stabilization in rhytidoplasty ${ }^{[65]}$, Auersvald et al. ${ }^{[6,67]}$ developed a hemostatic net for neck and face lifting.

This procedure was first utilized to treat minor hematomas, with maximum a diameter of $5 \mathrm{~cm}$. The procedure showed good results without complications. The authors then expanded the indication of the hemostatic net to treat large hematomas - where the net was also shown to be effective and safe. Given these encouraging results, Auersvald et al. ${ }^{[6]]}$ decided to use the net as a preventive method for hematomas. The Auersvalds' experience has demonstrated that this is the only safe method to prevent hematomas to date.

The net can be done with many interrupted sutures or with a running suture transfixing the skin and grasping the underling tissue [Supplementary Video 3]. The net is built using a mononylon 5-0 with a large needle of approximately $26 \mathrm{~mm}$. In thicker skin, a mononylon 4-0 can be used. The distance between sutures may vary but is typically between 8 and $10 \mathrm{~mm}^{[66]}$.

The net must remain in the patient for $48 \mathrm{~h}$ after surgery. During this time, it is possible to use occlusive bandage to hide the appearance of the net and maintain the sutures in a clean environment ${ }^{[66]}$. The dressing removal is preceded by a skin cleaning with chlorhexidine.

The literature reports no cases of hematomas when the net has been used, which demonstrates the efficacy of the net ${ }^{[6-69]}$. The mechanisms that explain these results include obliteration of the "dead space", pressure on the SMAS-platysma by the skin, and flap stability ${ }^{[66]}$. The postoperative recovery is safer and involves 


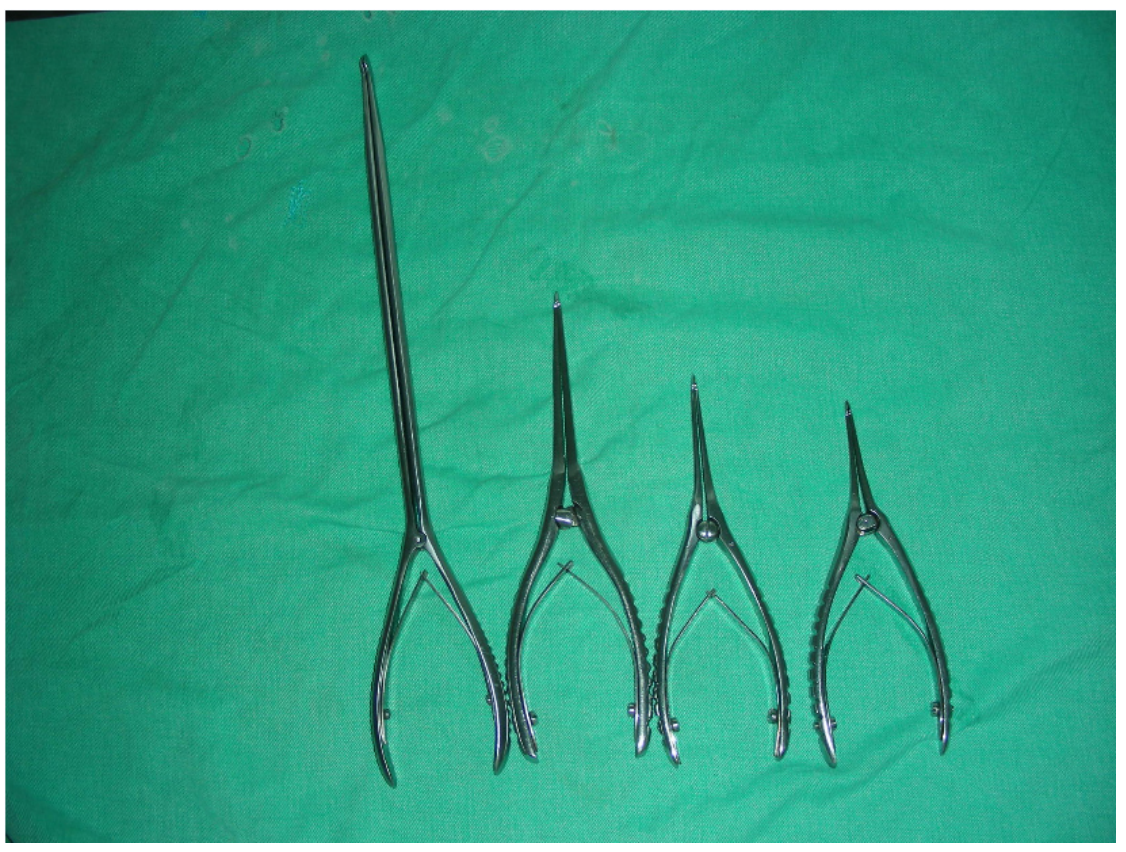

Figure 6. Viterbo's dissectors. Produced by Faga Medical.

fewer complications. This has encouraged surgeons to perform more extensive undermining in the neck, leading to better results ${ }^{[68]}$.

Other important advantages of the net beyond the likely zero hematoma risk involves skin mobilization, redraping, and accommodation. This has important implications for patients who have necks with severe wrinkles and laxity skin ${ }^{[68,70-72]}$.

The net allowed Viterbo et al. ${ }^{[70]}$ to create the gliding brow lift, a new technique to elevate and reshape the brows with a $3 \mathrm{~mm}$ incision. The skin is pulled in the frontal lower part elevating the brow, and the excess skin in the upper part is "shrunken" by the net ${ }^{[70]}$ [Supplementary Video 4].

Sozer ${ }^{[73]}$ used the net in neck lifting with minimal incisions, and only in the submental area. Through the incision, he dissected all the neck skin, and, with the net, he re-draped the skin by doing a traction in the central skin and by accommodating the skin laterally ${ }^{[73]}$.

The hemostatic net does, however, increase the risk of other complications, including necrosis and ischemia ${ }^{[6-71]}$. To prevent skin loss during the suture and $2 \mathrm{~h}$ postoperative period, the surgical team should observe the skin color in the area where the net has been applied. If the skin turns white, the suture in this limited space should be cut but not removed and must be observed to see whether it returns to its normal color $^{[70]}$.

The use of intraoperative laser angiography has evidenced the safety of this technique when it comes to flap vascularization. A study showed that a neck flap with $89 \%$ perfusion before surgery had $85 \%$ in post net application $^{[68]}$. 
No facial palsy or nerve impairment has been described as a complication of this technique. In addition, since this procedure involves external suture, the net can be removed or relocated in cases where alterations are noticed ${ }^{[69,74]}$.

The incidence of scars made by the net is minimal. The Fitzpatrick types influence inflammatory hyperpigmentation, and dark skin patients have higher risk to develop this condition. However, it is usually a self-limited condition that is resolved 3-5 months after the procedure. Laser and bleaching creams speed up resolution ${ }^{[67,70]}$. Persistent hypopigmentation has been related to the net in three cases in the retroauricular area, but it has been barely evident ${ }^{[64]}$. Despite these possible scarring complications, quilting suture does improve healing in the neck-lifting incision ${ }^{[75]}$.

The net appearance is an important concern. The literature does not report patient rejection based on appearance alone ${ }^{[68]}$. Extensive explanation, pictures of previous procedures, and $48 \mathrm{~h}$ occlusive bandage can all increase patient acceptance ${ }^{[67]}$.

The hemostatic net does not cause a significant increase in surgical time. The procedure can range from 15 to $35 \mathrm{~min}^{[68]}$. Compared to the risk of hematomas, this additional time is worth the benefit.

The first publications on hemostatic net suggests that plastic surgeons who wants to introduce this procedure should focus first on high-risk patients ${ }^{[66]}$. However, this technique has been shown to be reproducible and safe, and it has good results, including those observed in plastic surgery training $\operatorname{programs}^{[69]}$.

\section{CONCLUSION}

The evolution of neck-lifting techniques has led to improved outcomes, including patient's self-esteem. This review evidences the use of multiple safe surgeries, during which patients with the right indication have minimal chances of complications. We highlight the importance of hematomas and their prevention during neck-lifting procedures. The hemostatic net has emerged as a safe and reliable technique that could be used to prevent hematomas. Future prospective and retrospective studies should evaluate the patient perception of this technique and the safety of its use.

\section{DECLARATIONS}

\section{Authors' contributions}

Made substantial contributions to conception and design of the study and performed data analysis and interpretation: Viterbo F, Secanho MS

Performed data acquisition, as well as provided administrative, technical, and material support: Viterbo F, Secanho MS

\section{Availability of data and materials}

Not applicable.

\section{Financial support and sponsorship}

None.

\section{Ethical approval and consent to participate}

Not applicable. 


\section{Conflicts of interest}

Both authors declared that there are no conflicts of interest.

\section{Consent for publication}

All the pictures had consent of the patients for publication.

\section{Copyright}

(C) The Author(s) 2021.

\section{REFERENCES}

1. Braz A, Eduardo CCP. Reshaping the lower face using injectable fillers. Indian J Plast Surg 2020;53:207-18. DOI PubMed PMC

2. Goodman G J. The oval female facial shape--a study in beauty. Dermatol Surg 2015;41:1375-83. DOI PubMed

3. Coleman SR, Grover R. The anatomy of the aging face: volume loss and changes in 3-dimensional topography. Aesthet Surg $J$ 2006;26:S4-9. DOI PubMed

4. Cotofana S, Fratila AA, Schenck TL, Redka-Swoboda W, Zilinsky I, Pavicic T. The anatomy of the aging face: a review. Facial Plast Surg 2016;32:253-60. DOI PubMed

5. Shaw RB Jr, Katzel EB, Koltz PF, et al. Aging of the facial skeleton: aesthetic implications and rejuvenation strategies. Plast Reconstr Surg 2011;127:374-83. DOI PubMed

6. Naini FB, Cobourne MT, McDonald F, Wertheim D. Submental-cervical angle: perceived attractiveness and threshold values of desire for surgery. J Maxillofac Oral Surg 2016;15:469-477. DOI PubMed PMC

7. Bravo FG. Reduction Neck Lift: The importance of the deep structures of the neck to the successful neck lift. Clin Plast Surg 2018;45:485-506. DOI PubMed

8. Castro CC, Aboudib JH Jr, Roxo AC. Updating the concepts on neck lift and lower third of the face. Plast Reconstr Surg 2012;130:199-205. DOI PubMed

9. Marten T, Elyassnia D. Neck lift: defining anatomic problems and choosing appropriate treatment strategies. Clin Plast Surg 2018;45:455-84. DOI PubMed

10. Sunder S. Relevant topical skin care products for prevention and treatment of aging skin. Facial Plast Surg Clin North Am 2019;27:413-8. DOI PubMed

11. Doh EJ, Kim J, Lee DH, Park JY. Neck rejuvenation using a multimodal approach in Asians. J Dermatolog Treat 2018;29:400-4. DOI PubMed

12. Haddad A, Menezes A, Guarnieri C, et al. Recommendations on the use of injectable poly-l-lactic acid for skin laxity in off-face areas J Drugs Dermatol 2019;18:929-935. PubMed

13. Fabi SG. Noninvasive skin tightening: focus on new ultrasound techniques. Clin Cosmet Investig Dermatol 2015;8:47-52. DOI PubMed PMC

14. DiBernardo GA, DiBernardo BE. Prediction of treatment outcomes for neck rejuvenation utilizing a unique classification system of treatment approach using a 1440-nm side-firing laser. Aesthet Surg J 2018;38:S43-51. DOI PubMed

15. Mustoe TA, Rawlani V, Zimmerman H. Modified deep plane rhytidectomy with a lateral approach to the neck: an alternative to submental incision and dissection. Plast Reconstr Surg 2011;127:357-70. DOI PubMed

16. Gerecci D, Perkins SW. The graduated approach to surgical neck contouring. Facial Plast Surg 2019;35:516-24. DOI PubMed

17. Feldman JJ. Neck lift. St. Louis: Quality Medical; 2006.

18. Knize DM. Limited incision submental lipectomy and platysmaplasty. Plast Reconstr Surg 2004;113:1275-8. DOI PubMed

19. Marten T, Elyassnia D. Short scar neck lift: neck lift using a submental incision only. Clin Plast Surg 2018;45:585-600. DOI PubMed

20. Ramírez OM. Advanced considerations determining procedure selection in cervicoplasty. Part one: anatomy and aesthetics. Clin Plast Surg 2008;35:679-90, viii. DOI PubMed

21. Rohrich RJ, Rios JL, Smith PD, Gutowski KA. Neck rejuvenation revisited. Plast Reconstr Surg 2006;118:1251-63. DOI PubMed

22. Feldman JJ. Neck lift my way: an update. Plast Reconstr Surg 2014;134:1173-83. DOI PubMed

23. Cristel RT, Irvine LE. Common complications in rhytidectomy. Facial Plast Surg Clin North Am 2019;27:519-27. DOI PubMed

24. Mendelson BC, Tutino R. Submandibular gland reduction in aesthetic surgery of the neck: review of 112 consecu- tive cases. Plast Reconstr Surg 2015;136:463-71. DOI

25. Auersvald A, Auersvald LA. Innovative tactic in submandibular salivary gland partial resection. Plast Reconstr Surg Glob Open 2015;2:e274. DOI PubMed PMC

26. Auersvald A, Auersvald LA, Oscar Uebel C. Subplatysmal necklift: a retrospective analysis of 504 patients. Aesthet Surg J 2017;37:111. DOI PubMed

27. Auersvald A, Auersvald LA. Management of the submandibular gland in neck lifts: indications, techniques, pearls, and pitfalls. Clin Plast Surg 2018;45:507-25. DOI PubMed

28. Pelle-Ceravolo M, Angelini M, Silvi E. Complete platysma transection in neck rejuvenation: a critical appraisal. Plast Reconstr Surg 2016;138:781-91. DOI PubMed

29. Guerrerosantos J. Managing platysma bands in the aging neck. Aesthet Surg J 2008;28:211-6. DOI PubMed 
30. Daher JC. Closed platysmotomy: a new procedure for the treatment of platysma bands without skin dissection. Aesthetic Plast Surg 2011;35:866-77. DOI PubMed PMC

31. Gonzalez R. Simplified closed platysmotomy. Aesthet Surg J 2010;30:489-90. DOI PubMed

32. Fournier PF, Carrera C. Closed section of anterior platysmal ribbons under local anesthesia. Rev Chir Esthet 2005;131:29-40.

33. Ellenbogen R, Karlin JV. Regrowth of platysma following platysma cervical lift: etiology and methodology of prevention. Plast Reconstr Surg 1981;67:616-23. DOI PubMed

34. Hwanng K. Surgical anatomy of the facial nerve relating to facial rejuvenation surgery. J Craniofac Surg 2014;25:1476-81. DOI PubMed

35. Feldman JJ. Corset platysmaplasty. Plast Reconstr Surg 1990;85:333-43. DOI PubMed

36. Ramirez OM. Cervicoplasty: nonexcisional anterior approach. Plast Reconstr Surg 1997;99:1576-85. PubMed

37. Labbé D, Giot JP, Kaluzinski E. Submental area rejuvenation by digastric corset: anatomical study and clinical application in 20 cases. Aesthetic Plast Surg 2013;37:222-31. DOI PubMed

38. Labbé D, Franco RG, Nicolas J. Platysma suspension and platysmaplasty during neck lift: anatomical study and analysis of 30 cases. Plast Reconstr Surg 2006;117:2001-7; discussion 2008-10. DOI PubMed

39. Fogli AL. Skin and platysma muscle anchoring. Aesthetic Plast Surg 2008;32:531-41. DOI PubMed

40. Gonzalez R. The LOPP-lateral overlapping plication of the platysma: an effective neck lift without submental incision. Clin Plast Surg 2014;41:65-72. DOI PubMed

41. Ramanadham SR, Mapula S, Costa C, Narasimhan K, Coleman JE, Rohrich RJ. Evolution of hypertension management in face lifting in 1089 patients: optimizing safety and outcomes. Plast Reconstr Surg 2015;135:1037-43. DOI PubMed

42. Baker DC, Stefani WA, Chiu ES. Reducing the incidence of hematoma requiring surgical evacuation following male rhytidectomy: a 30-year review of 985 cases. Plast Reconstr Surg 2005;116:1973-85; discussion 1986-7. DOI PubMed

43. Niamtu J 3rd. Expanding hematoma in face-lift surgery: literature review, case presentations, and caveats. Dermatol Surg 2005;31:1134-44. PubMed

44. Grover R, Jones BM, Waterhouse N. The prevention of haematoma following rhytidectomy: a review of 1078 consecutive facelifts. $\mathrm{Br}$ J Plast Surg 2001;54:481-6. DOI PubMed

45. Kleinberger AJ, Spiegel JH. What is the best method for minimizing the risk of hematoma formation after rhytidectomy? Laryngoscope 2015;125:534-6. DOI PubMed

46. Jones BM, Grover R. Avoiding hematoma in cervicofacial rhytidectomy: a personal 8-year quest. Reviewing 910 patients. Plast Reconstr Surg 2004;113:381-7; discussion 388-90. DOI PubMed

47. Stuzin JM. MOC-PSSM CME article: face lifting. Plast Reconstr Surg 2008;121:1-19. DOI PubMed

48. Maricevich MA, Adair MJ, Maricevich RL, Kashyap R, Jacobson SR. Facelift complications related to median and peak blood pressure evaluation. Aesthetic Plast Surg 2014;38:641-7. DOI PubMed

49. Batniji RK. Complications/sequelae of neck rejuvenation. Facial Plast Surg Clin North Am 2014;22:317-20. DOI PubMed

50. Jones BM, Grover R, Hamilton S. The efficacy of surgical drainage in cervicofacial rhytidectomy: a prospective, randomized controlled trial. Plast Reconstr Surg 2007;120:263-70. DOI PubMed

51. Giordano S, Koskivuo I, Suominen E, Veräjänkorva E. Tissue sealants may reduce haematoma and complications in face-lifts: a metaanalysis of comparative studies. J Plast Reconstr Aesthet Surg 2017;70:297-306. DOI PubMed

52. Kanazawa R, Sato S, Iwamoto N, Teramoto A. Allergic reaction following arachnoid plasty with a fibrin sealant. Neurol Med Chir 2010;50:608-10. DOI PubMed

53. Kober BJ, Scheule AM, Voth V, Deschner N, Schmid E, Ziemer G. Anaphylactic reaction after systemic application of aprotinin triggered by aprotinin-containing fibrin sealant. Anesth Analg 2008;107:406-9. DOI PubMed

54. Wan D, Dayan E, Rohrich RJ. Safety and adjuncts in face lifting. Plast Reconstr Surg 2019;144:471e-84e. DOI PubMed

55. Baker DC, Conley J. Avoiding facial nerve injuries in rhytidectomy. Anatomical variations and pitfalls. Plast Reconstr Surg 1979;64:781-95. DOI PubMed

56. Wan D, Small KH, Barton FE. Face lift. Plast Reconstr Surg 2015;136:676e-89e. DOI PubMed

57. Bloom JD, Immerman SB, Rosenberg DB. Face-lift complications. Facial Plast Surg 2012;28:260-72. DOI PubMed

58. Rees TD, Liverett DM, Guy CL. The effect of cigarette smoking on skin-flap survival in the face lift patient. Plast Reconstr Surg 1984;73:911-5. DOI PubMed

59. Vasconez LO. Facelifting. XXIX Jornada Carioca de Cirurgia Plástica; 2010 Aug 7; Rio de Janeiro, RJ, Brazil.

60. da Luz DF, Wolfenson M, Figueiredo J, Didier JC. Full-face undermining using progressive dilators. Aesthetic Plast Surg 2005;29:959. DOI PubMed

61. Trepsat F. Volumetric face lifting. Plast Reconstr Surg 2001;108:1358-70; discussion 1371-9. DOI PubMed

62. Viterbo F. Improved blunt dissectors for greater safety in face lift surgery. Plast Reconstr Surg 2013;131:858e-9e. DOI PubMed

63. Raghavan U, Daoud M, Ullas G. Face and neck lift-postoperative care. Facial Plast Surg 2018;34:561-9. DOI PubMed

64. Baroudi R, Ferreira CA. Seroma: how to avoid it and how to treat it. Aesthet Surg J 1998;18:439-41. DOI PubMed

65. Pontes R. O universo da ritidoplastia. Rio de Janeiro: Revinter; 2011.

66. Auersvald A, Auersvald LA, Biondo-Simões MLP. Hemostatic net: an alternative for the prevention of hematoma in rhytidoplasty. Rev Bras Cir Plast 2010;27:22-30. DOI

67. Auersvald A, Auersvald LA. Hemostatic net in rhytidoplasty: an efficient and safe method for preventing hematoma in 405 consecutive patients. Aesthetic Plast Surg 2014;38:1-9. DOI PubMed 
68. O'daniel TG, Auersvald A, Auersvald LA. Hemostatic net in facelift surgery. MKG-Chirurg 2019;12:78-85. DOI

69. Fasolin F, Webster RS, Gasperin B, Krauterbluth Solano PE, Castro Althoff GC, Binsely P. Abstract: hemostatic net. Plast Reconstr Surg Glob Open 2017;5:188. DOI

70. Viterbo F, Auersvald A, O'Daniel TG. Gliding brow lift (GBL): a new concept. Aesthetic Plast Surg 2019;43:1536-46. DOI PubMed

71. Abdulshakoor A, Labbe D. Cervicomental angle definition in the youthful patient (less than 40 years). Ann Chir Plast Esthet 2021;66:69-75. DOI PubMed

72. O'daniel TG, Kachare SD. Deep neck lifting. Advances in Cosmetic Surgery 2020;3:189-208. DOI PubMed

73. Sozer O. Personal approach to necklift. 1st Annual Periorbital \& Facial Symposium; 2020 Jan 23; Atlanta, USA.

74. Ballan A, Jabbour S, El Rayess Y, Jabbour K, El Hachem L, Nasr M. Quilting sutures in rhytidectomy: a systematic review of the literature. Aesthet Surg J 2020;40:1157-64. DOI PubMed

75. Hudson DA. The quilting suture: its application in face lifts. Plast Reconstr Surg 2010;126:72e-3e. DOI PubMed 